\title{
A Quantitative Study of the Carbon Monoxide Formed During the Absorption of Oxygen by Alkaline Pyrogallol
}

\author{
By Marthada V. Kilday
}

\begin{abstract}
The amounts of carbon monoxide evolved during analytical absorptions of oxygen by alkaline pyrogallol were studied with respect to the composition and methods of preparing solutions, the temperature of reaction, the rate of flow of the sample through the solution, the capacity of the reagent for the absorption of oxygen, the partial pressure of reacting oxygen, and the manner of bringing the gas into contact with the reagent. Less than 0.02 percent of carbon monoxide was formed during analyses of gases containing as much as 80 percent of oxygen when the recommended solutions were used in bubbler-type absorption pipettes, and when the samples were passed into the solutions at a rate greater than 20 milliliters per minute at about $25^{\circ} \mathrm{C}$. This was true until the solutions had absorbed approximately twelve times their volume of oxygen, after which the formation of carbon monoxide increased significantly. The NBS colorimetric carbon monoxide indicating gel was used for the quantitative determinations of carbon monoxide. A method was developed for preparing pyrogallol solutions that yielded reproducible amounts of carbon monoxide so small that no significant error was caused in the usual analysis.
\end{abstract}

\section{Introduction}

For many years it has been known that under some conditions the analytical absorption of oxygen by alkaline pyrogallol is subject to an error introduced by the formation of carbon monoxide during the reaction. This carbon monoxide is measured as part of the residue after absorption, so that the oxygen absorbed appears to be less than was actually present in the original sample. If a combustion analysis follows, the carbon monoxide may contribute further error.

Pyrogallol is so superior to other reagents sometimes employed for the removal of oxygen, with respect to the exchange of gases inert to it, that errors of physical solubility are very greatly reduced by its use [1]. ${ }^{1}$ However, the evolution of carbon monoxide has long been invoked as an argument against the use of pyrogallol. It will be shown in this paper that this argument is

\footnotetext{
1 Figures in brackets indicate the literature references at the end of this paper.
}

unfounded, as no significant amount of carbon monoxide is formed under the conditions of the usual analysis when the recommended solutions are used.

Many investigators have tried to determine the amount of carbon monoxide formed under the conditions of the conventional analytical procedures, but usually they have found that the concentration of carbon monoxide was too low for the methods of analysis employed. Therefore they have resorted to measuring the relatively large amounts of carbon monoxide produced under extreme conditions, such as high partial pressures of oxygen, weakly alkaline pyrogallol solutions, and high temperatures of reaction. Even with these high concentrations of carbon monoxide, which came within the range of their analytical methods, there was a great divergence in the results obtained by various investigators.

During World War II, this Bureau developed a colorimetric indicator for the quantitative determination of carbon monoxide in low concentrations 
up to 0.1 percent. Higher concentrations were determined by making simple dilutions of the samples [2].

The NBS indicator was found to be very satisfactory in the direct analyis of the carbon monoxide present in the residues of oxygen absorptions by pyrogallol. During the preliminary work, it was found that, although a given solution yielded reproducible amounts of carbon monoxide during a series of like analyses, there was significant variation in the amount of carbon monoxide generated by different solutions prepared according to the same formula. This led to an investigation of the methods of preparing the pyrogallol solutions. By dissipating the heat produced while dissolving the pyrogallol in a saturated solution of potassium hydroxide, solutions were prepared that not only gave reproducible results with respect to carbon monoxide generated, but which consistently evolved less carbon monoxide during an absorption.

A satisfactory method of preparing the pyrogallol solutions having been established, it was possible to proceed with the determination of carbon monoxide evolved under various conditions. The data obtained in this experimental study are reported so that the gas analyst may use them in estimating the error to be expected as a result of carbon monoxide formation under the conditions of the analysis.

\section{Description of Apparatus}

A modification of the Shepherd gas analysis apparatus [3] with spherical, interchangeable ground-glass joints instead of rubber connections was used in this study, and Apiezon grease "L" was the stopcock lubricant employed. Figure 1 is a diagram of the distributor as modified for this work. Below stopcock 1 is the absorption pipette. Two mercury reservoirs, connected under stopcocks 2 and 3, were used for diluting and mixing the residues from the absorptions of oxygen, which were too rich in carbon monoxide to be analyzed directly with the NBS colorimetric indicator. Below stopcock 4 is a tube containing gold sponge to remove mercury vapor, which interferes with the test for carbon monoxide. The colorimetric carbon monoxide indicator tube was attached with a pure gum rubber connection below the gold sponge. Between stopcocks 5 and 6 was a cali-

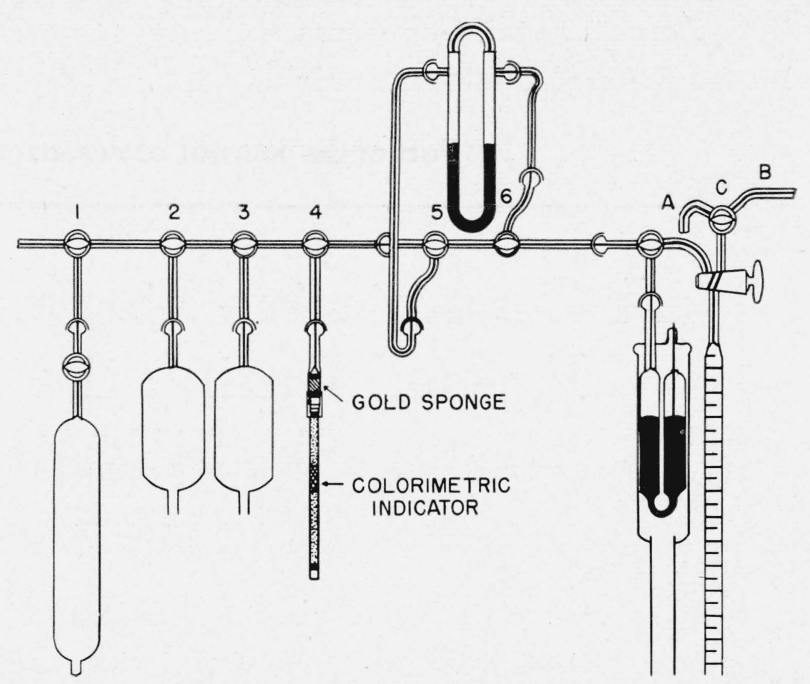

Figure 1. Distributor showing modifications provided for the carbon monoxide determination and for measuring the rate of flow of the gas.

brated flowmeter that was provided to measure the rate of flow of the residue after absorption through the carbon monoxide indicator tube. The position of the stopcocks could be manipulated so that the flowmeter containing mercury was either included or excluded from the distributor train. The burette and compensator were previously described [4].

The volumetric analyses were made in a laboratory where the temperature was maintained at about $25^{\circ} \mathrm{C}$. The room was reserved primarily for making physical measurements and was therefore free of the atmosphereic contaminations and variations present in many chemical laboratories.

The nine types of absorption pipettes used in this investigation are shown in figure 2 .

\section{Method for Determination of Carbon Monoxide}

The NBS colorimetric indicator for carbon monoxide and the "Laboratory Method" described by Shepherd [2] were used in the analyses for carbon monoxide reported in this paper. A detailed description of the analytical procedure as adapted to this problem is given in section $\mathrm{V}$.

The chemicals of the indicator tube are inclosed in a $15-\mathrm{cm}$ length of $7-\mathrm{mm}$ Pyrex glass tubing. The 2-cm length of yellow indicating gel, which turns green upon exposure to carbon monoxide, is protected at both ends by a 5-cm length of purified silica gel, which removes water vapor and 

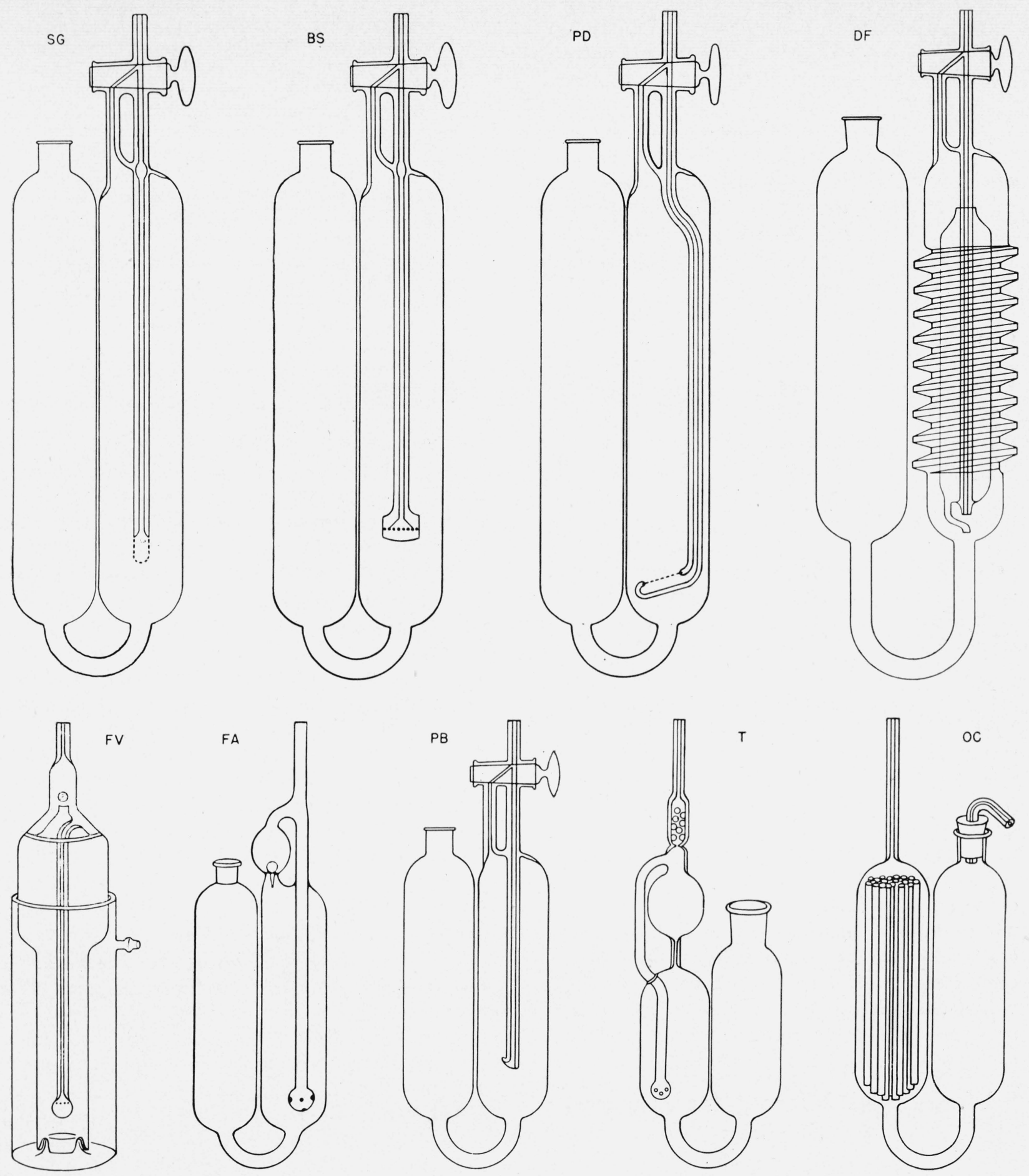

Figure 2. Absorption pipettes. Sintered-glass bubbler $(S G) ;$ Branham-Sperling bubbler (BS); platinum-disk bubbler (PD); Dennis-Friedrichs $(D F)$; Fisher valve-bubbler $(F V)$; Francis autobubbler $(F A)$; Hankus or plain bubbler $(P B)$; Tramm double-action $(T)$; Orsat contact $(O C)$. 
organic vapors that might interfere with the determination of carbon monoxide. The guard gel is held in place by absorbent cotton, and a cork is placed in each end when the tube is not actually being used.

To determine the percentage of carbon monoxide present in an unknown sample, a measured volume of the sample is passed through the indicator tube at a controlled rate of flow. The color developed by the indicating gel is compared with standards prepared by exposing tubes to known concentrations of carbon monoxide. The percentage of carbon monoxide expressed in this paper is based on the volume of the original sample and refers to the amount of carbon monoxide that would have been generated by $100 \mathrm{ml}$ of original sample. In other words, if it is stated that a solution generated 0.02 percent of carbon monoxide, it means that $0.02 \mathrm{ml}$ of carbon monoxide would have been present in the residue of absorption of $100 \mathrm{ml}$ of original sample.

In this work there was a linear relationship between the concentration of carbon monoxide and the probable error of the carbon monoxide determination. From 0.0020 to 0.039 percent of carbon monoxide, the error was about 17 percent of the carbon monoxide present. These errors could have been reduced to less than half of these values (1) by reducing the interval of time in exposing standards to the known mixtures of carbon monoxide and (2) by having the concentration of carbon monoxide in the known mixtures nearly the same as the partial pressure of carbon monoxide that exists in the unknown. These refinements were not employed in this work because most volumetric gas analysis apparatus are not capable of such accuracy. If the analyst is concerned with extreme accuracy, a determination of carbon monoxide should be made for each individual analysis, as there is some variation in the amount of carbon monoxide produced even when the conditions of the analyses are similar.

\section{General Methods for Preparing Solutions}

Prior to the present study, the gas chemistry laboratory had used a method of preparing pyrogallol solutions that was previously described [3] and is quoted below (page 145 of this reference):

The reagent used for the removal of oxygen in the absorption pipette...(platinum-disk bubbler) is an alkaline pyrogallol solution. This is made by dissolving crystalline pyrogallol in a minimum amount of hot water and adding this solution to the concentrated potassium hydroxide solution ... The resulting solution closely approximates one recommended by Anderson, ${ }^{8}$ who found a solution containing $15 \mathrm{~g}$ of pyrogallol per $100 \mathrm{ml}$ of potassium hydroxide solution of 1.55 specific gravity to be satisfactory. . .

In order to prevent air from reaching the reagents a layer of light mineral oil, about 10 to $15 \mathrm{~mm}$ in depth, is poured over the reagent in the reservoir arm of the pipette. This also permits the preparation of the pyrogallol solution within the pipette itself and out of contact with air. The potassium hydroxide solution is first introduced, the oil is placed over this solution and the pyrogallic acid solution in water is introduced beneath the layer of oil from a pipette.

${ }^{8}$ Anderson, R. P., Ind. Eng. Chem. 7, p. 588 (1915).

It was necessary to heat the pyrogallol crystals with water in order to prepare the solution within a reasonable length of time, and this solution, while still hot, was poured through a long-stemmed funnel to the bottom of the saturated potassium hydroxide solution in the pipette. This was frequently accompanied by considerable bubbling and splattering as a result of the additional heat produced during solution.

Preliminary work of this study indicated that this method of preparation produced solutions yielding inconsistent results with respect to the concentration of carbon monoxide evolved. Consequently, an improved method was developed that produced solutions that yielded reproducible amounts of carbon monoxide when used under similar conditions. This solution, quite happily, yielded significantly less carbon monoxide than previous solutions. A description of the improved method follows.

The saturated potassium hydroxide solution is prepared by saturating distilled water with solid potassium hydroxide at $25^{\circ} \pm 1^{\circ} \mathrm{C}$. This solution contains about 55 percent of potassium hydroxide, or $120 \mathrm{~g}$ of potassium hydroxide per 100 $\mathrm{g}$ of water, and has a specific gravity of about 1.55 .

The flask or pipette in which the pyrogallol is to be stored is placed in an ice bath, and the pyrogallol crystals are placed in the bottom of the container. The saturated solution of potassium hydroxide is added rapidly, and the flask is sealed with an air-tight cover, or a layer of light mineral oil is added if the solution is prepared in a pipette. The new solution should remain in the bath until 
the ice melts and the bath reaches room temperature, at which time it may be used immediately or stored for future use. If any crystals remain undissolved, agitating the solution in the pipette by passing nitrogen into it will complete solution. Data will be presented that show no significant difference in the amount of carbon monoxide formed by solutions that were freshly prepared and those that were stored out of direct sunlight for as long as 21 months.

\section{Procedure for Analyses}

In the course of this study, five partial pressures of oxygen were used: approximately 21 (air), 40, 60,80 percent of oxygen in nitrogen, and 100 percent of oxygen. Air was sampled directly from the laboratory in which the analyses were made, and the other mixtures and the approximately pure oxygen were stored under pressure in gas cylinders from which samples were taken in the following manner. A needle valve was used to control the sampling rate, and the sample was passed through copper tubing to $A$, figure 1 , and connected by means of nitrometer pressure tubing. The sample was thoroughly flushed from $A$ through $B$, and stopcock $C$ was turned to admit the sample under pressure to the mercury-filled burette.

The sample was saturated with water vapor from the burette walls, and the volume was measured in the usual way. Unless otherwise stated, the rate of flow of the gas to the absorption pipette was controlled only by the maximum rate at which the mercury could flow into the burette and by the back pressure exerted in the pipette; this was usually about 190 to $250 \mathrm{ml} / \mathrm{min}$. After enough passes had been made into the pyrogallol to assure complete absorption of the oxygen, the residue was returned to the burette, saturated, and measured as before.

From this point the procedure depended upon the total volume of the residue as well as the concentration of carbon monoxide. Dilution was necessary if the amount of carbon monoxide exceeded 0.04 percent, or if the residual volume was less than $70 \mathrm{ml}$, which was the minimum set for each determination in this work. If no dilution was needed, the determination of carbon monoxide was made immediately.

When the volume of the residue was too small, it was measured at atmospheric pressure and air was drawn into the burette. The volume of the result- ing mixture was also measured at atmospheric pressure, and the concentration of carbon monoxide present in the residue was computed.

If the concentration of carbon monoxide in the residue after absorption was expected to exceed the range of the colorimetric carbon monoxide indicator, a fraction of the residue was stored in one of the mercury reservoirs, and the remaining portion was diluted and treated as in the procedure described above. If further dilution was necessary, the second mercury reservoir was used to store the residue from the first dilution, and a measured volume of air was taken into the burette and mixed with the first diluted residue.

The amount of carbon monoxide in the residue or in the diluted residue was determined as follows. Six indicator tubes were used in the analysis, one for the residue and five for color standards. An indicator tube was attached to the volumetric gas analysis apparatus as shown in figure 1. The distributor was flushed, and $45 \mathrm{ml}$ of the residue was passed through the indicator tube at $90 \mathrm{ml} / \mathrm{min}$, which is equal to a 30 -sec exposure. The standards were prepared by passing a known concentration of carbon monoxide through indicator tubes at $90 \mathrm{ml} / \mathrm{min}$ for varying periods of time-usually at 5-sec intervals. The five standard mixtures of carbon monoxide in air were: $0.0025_{7}, 0.0052,0.0097,0.020_{2}$, and $0.038_{2}$ percent. The percentage of carbon monoxide in the unknown (residue) was determined by comparing visually the color developed in this tube with the colors of the tubes that had been exposed to known concentrations of carbon monoxide.

\section{Data and Discussion}

\section{Effect of Variations in Pyrogallol Solutions}

(a) Experimental Methods of Preparation

An inspection of the graphs in figure 3 reveals the inconsistencies found in the amount of carbon monoxide formed by solutions prepared by the "old" method previously described. These graphs show the amount of carbon monoxide evolved during absorptions of oxygen from air by solutions of various compositions individually prepared in several platinum-disk bubbler pipettes (see table 1). It may be seen that the amounts of carbon monoxide evolved during absorptions of oxygen from air under similar conditions by any one solution (those in any one small block) were 

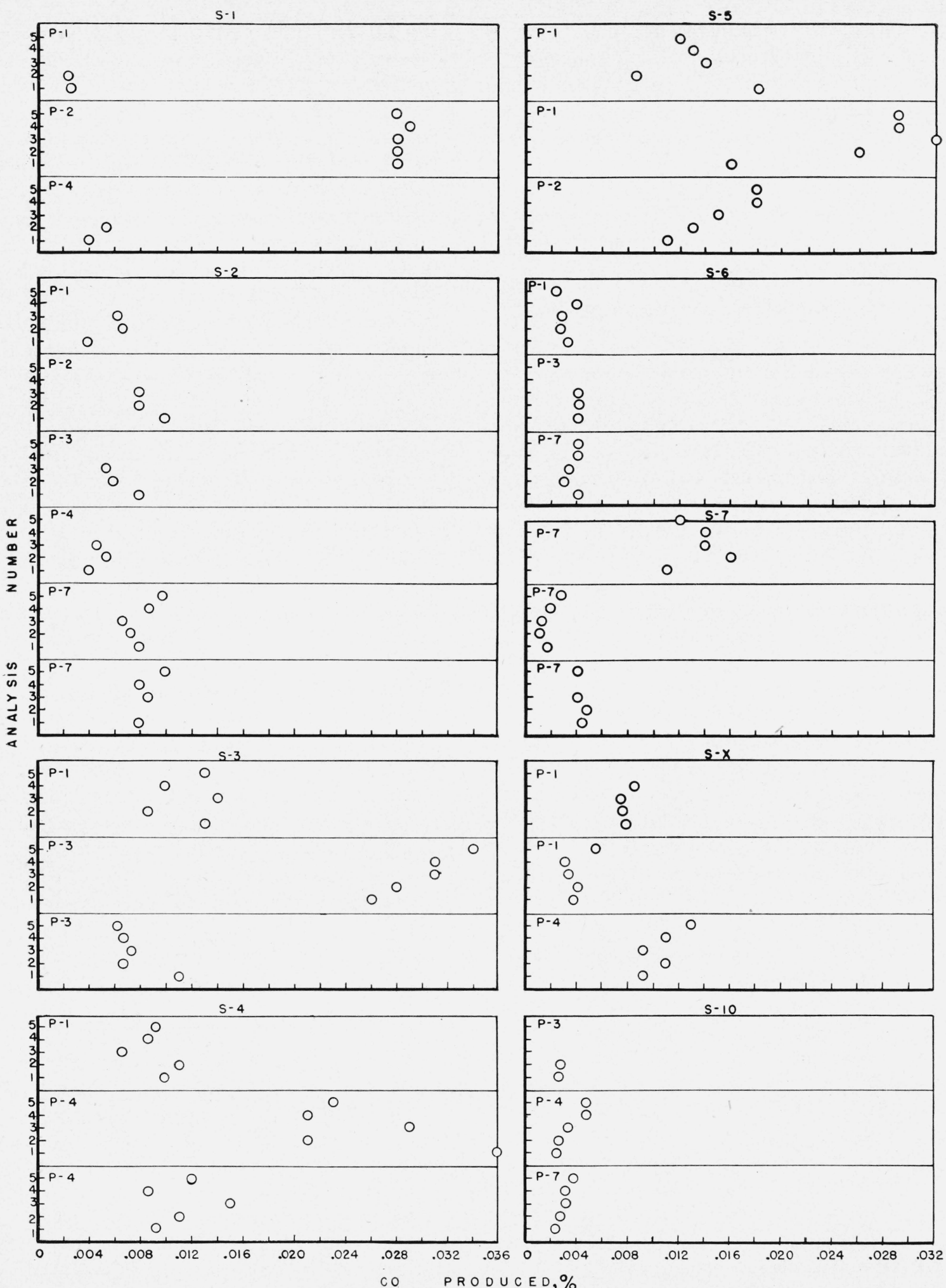

FIgURE 3. Percentage of carbon monoxide produced during absorption of oxygen from air by solutions prepared according to the old method.

Composition of the solutions are found in table 1. The number in the upper left-hand corner of each small block indicates which platinum-disk bubbler pipette was used. 
reasonably consistent, but in various solutions of the same composition (those in any one large block) the amount of carbon monoxide produced sometimes varied by as much as a factor of 10 .

TABle 1. Composition of solutions studied

\begin{tabular}{|c|c|c|c|c|}
\hline \multirow[b]{2}{*}{$\begin{array}{l}\text { Composi- } \\
\text { tion No. }\end{array}$} & \multirow[b]{2}{*}{$\begin{array}{c}\text { Pyro- } \\
\text { gallol a b }\end{array}$} & \multicolumn{2}{|c|}{ Solution } & \multirow{2}{*}{$\begin{array}{c}\text { Pyro- } \\
\text { gallol per } \\
100 \mathrm{ml} \text { of } \\
\text { Saturated } \\
\text { KOH so- } \\
\text { lution a o }\end{array}$} \\
\hline & & $\begin{array}{l}\text { Potassium } \\
\text { hydroxide } \\
\text { saturated } \\
\text { at } 25^{\circ} \mathrm{C}\end{array}$ & $\mathrm{H}_{2} \mathrm{O}$ & \\
\hline & $g$ & $m l$ & $m l$ & $g$ \\
\hline S-1_.... & 35 & 225 & 0 & 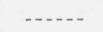 \\
\hline S-2..... & 35 & 200 & 25 & -..... \\
\hline S-3_.... & 35 & 175 & 50 & ....... \\
\hline S-4_.... & 35 & 150 & 75 & -...... \\
\hline S-5 & 35 & 125 & 100 & -...... \\
\hline S-6 _.-- & - - & - & - & 25 \\
\hline S-7_....- & - n..... & -........ & -....... & 20 \\
\hline $\mathrm{S}-\mathrm{X}^{\mathrm{d}} \mathrm{d}$ & -...... & -....... & -....... & 17 \\
\hline $\mathrm{S}-\mathrm{Z} \mathrm{d} \ldots$ & -....... & -...... & -...... & 14 \\
\hline S-10_... & -...... & -...-. & .......- & 5 \\
\hline $\mathrm{S}-\mathrm{B} 7 \ldots$ & (e) & (e) & (e) & (e) \\
\hline $\mathrm{S}-\mathrm{BZ} \mathrm{Z}_{-.}$ & $(f)$ & $(f)$ & $\left({ }^{(}\right)$ & $\left({ }^{(t)}\right.$ \\
\hline
\end{tabular}

s The crystalline pyrogallol was obtained commercially under the name "Acid pyrogallic, analytical reagent." When the old method of preparing solutions was used, an additional $10 \mathrm{ml}$ of water was added to dissolve the crystalline pryogallol.

b The amount of pyrogallol was equal to about $15.5 \mathrm{~g}$ of pyrogallol per $100 \mathrm{ml}$ of diluted solution of saturated potassium hydroxide. Thus the solutions of these compositions would logically be placed between solutions S-X and S-Z, except for the dilutions of the saturated potassium hydroxide solution.

- The concentration of potassium hydroxide was the same as that used in solution S-1, which was found to produce the least carbon monoxide in the series showing the effect of changing the concentration of potassium hydroxide in the solution.

$\mathrm{d}$ The only significance attached to $\mathrm{S}-\mathrm{X}$ and $\mathrm{S}-\mathrm{Z}$ is that the former was of a composition in general use by this laboratory before this work, and the latter was found to be the most desirable composition when the improved method of preparing solutions was used.

- 1 liter of solution S-7 stored in an Erlenmeyer flask and the cap sealed with paraffin.

$\{2$ liters of solution $\mathrm{S}-\mathrm{Z}$ stored in an Erlenmeyer flask and the cap sealed with Apiezon grease " $L$ ".

The fact that the variations were not caused by the use of different platinum-disk bubbler pipettes is shown in solutions $\mathrm{S}-3, \mathrm{~S}-4, \mathrm{~S}-5$, and S-7 where inconsistencies were found when the same pipette was used for different preparations of solutions of the same composition.

A thorough investigation was made of the possible causes for the variations shown in figure 3. First, the accuracy of the determination of carbon monoxide was verified by taking into the burette samples of a known concentration of carbon monoxide and determining the carbon monoxide present by the same method used in the analysis of the residues of absorption. In the ten analyses made, the maximum deviation from the known value was 10 percent of the carbon monoxide present, with an average deviation of 6 percent. The accuracy of the determination of carbon monoxide was therefore discounted as a significant variable. Other possible variables, which will be discussed in detail later, were:

1. Concentration of the solution with respect to pyrogallol.

2. Concentration of the solution with respect to potassium hydroxide.

3. Rate of flow of sample into pyrogallol solution.

4. Age of solution (actual age and also the degree expended).

5. Temperature of reaction during absorption of oxygen.

6. Number of passes into pyrogallol solution.

These factors were controlled sufficiently to eliminate them as significant variables in the runs represented in figure 3 . This left the actual method of preparing the pyrogallol solutions as the most probable cause of the extreme deviations.

It was believed that variations in the temperature of solutions might have caused differences in the solutions themselves, which in turn caused differences in the amount of carbon monoxide evolved during the absorption of oxygen in different runs. As the measurement of the maximum temperature developed at several points would have been rather difficult in this instance, the effect was shown by preparing solutions in which it was known that the temperature of the solution had been varied by large amounts.

Figure 4 shows the amount of carbon monoxide formed in absorptions from gaseous mixtures containing 21 percent and 80 percent of oxygen by solutions that were prepared in five different ways, each varying with respect to the temperature allowed to develop during preparation.

The greatest amount of carbon monoxide per unit volume of oxygen was evolved by the solution prepared by method 2 (see fig. 4) in which the pyrogallol was added all at once to the saturated potassium hydroxide solution at $53^{\circ} \mathrm{C}$ in an atmosphere of nitrogen. The yield of carbon monoxide was 0.023 to 0.059 percent during absorptions of oxygen from air. 


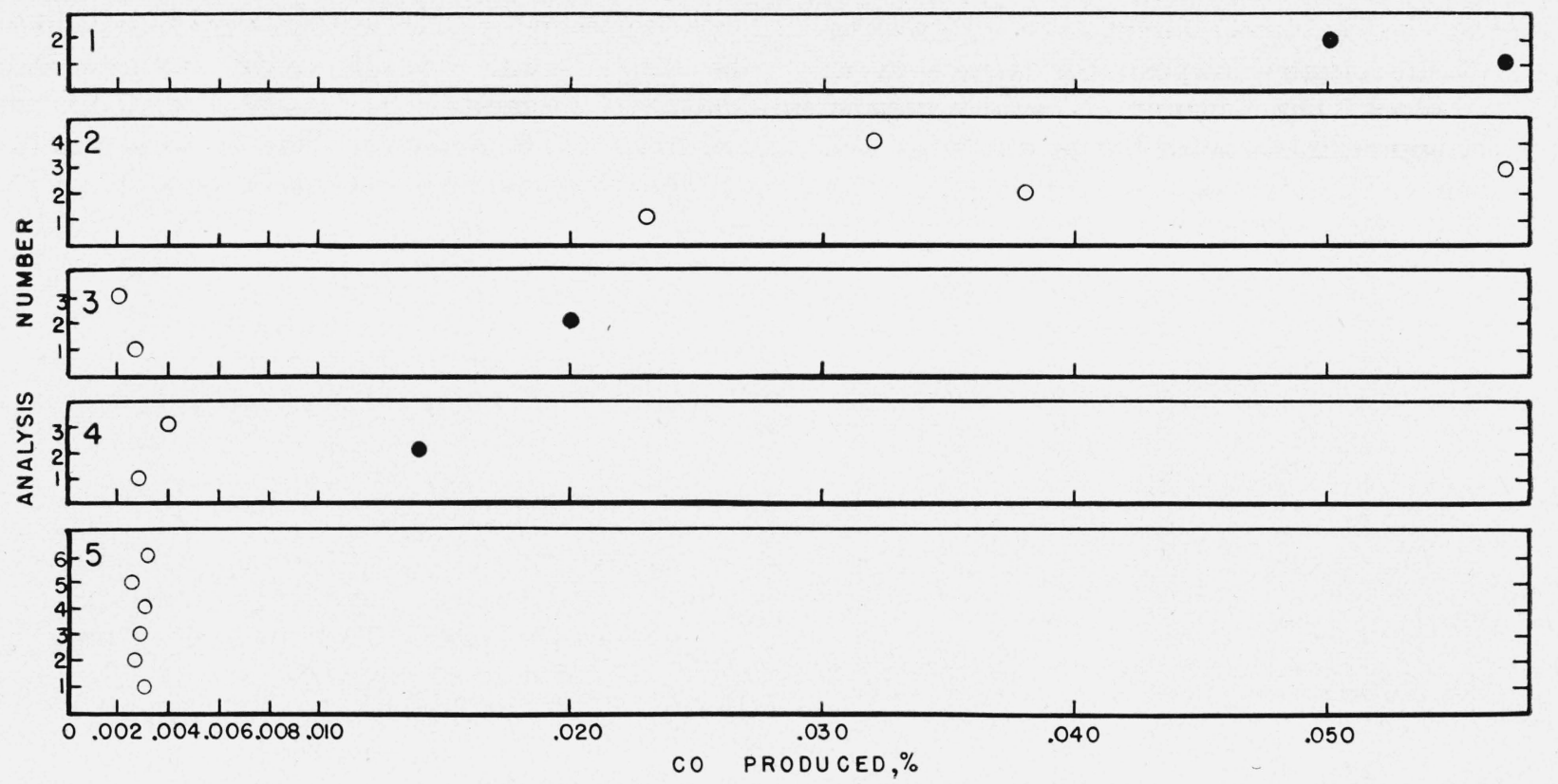

FIgure 4. Percentage of carbon monoxide produced durng absorption of oxygen by solutions prepared according to various methods.

The analysis number on the left shows the order in which the analyses were performed. The composition number of the solutions and the pipettes used are indicated as follows: $1, \mathrm{~S}-6, \mathrm{PD}-3$, method $1 ; 2, \mathrm{~S}-\mathrm{X}, \mathrm{SG}$, method $2 ; 3, \mathrm{~S}-\mathrm{X}, \mathrm{SG}$, method 3; 4, S-X, PD-4, method 4; 5, S-X, PD-7, method 5. $\bigcirc, 21 \%$ O (air);, $80 \% \mathrm{O}_{2}$ in $\mathrm{N}_{2}$.

In method 1 the pyrogallol was dissolved, by heating it with a little water (to approximately $110^{\circ} \mathrm{C}$ ), and added in small increments to the saturated potassium hydroxide solution at room temperature, with vigorous stirring after each addition. In this case, the dissipation of heat was more rapid, and the carbon monoxide evolved during the absorption from a mixture containing 80 percent of oxygen was about 0.05 to 0.06 percent, which is of the same order as that produced by the previously described solution when only 21 percent of oxygen was absorbed. Since the higher partial pressure of oxygen will produce more carbon monoxide in the same solution, it was assumed that the carbon monoxide evolved by the solutions during absorptions was probably dependent to some extent upon the rapidity of the dissipation of heat during the preparation of the pyrogallol solutions.

In preparing the solution according to method 3, it was found unnecessary to dissolve the pyrogallol crystals in water, as previously described, before adding them to the saturated potassium hydroxide solution. The solution was made by simply adding the crystalline pyrogallol to the saturated solution of potassium hydroxide at room temperature and placing the mixture in a refrigerator overnight to accelerate the dissipation of the heat of reaction. Here the carbon monoxide evolved was reduced by more than half of that found in method 1 in the absorption from a mixture containing 80 percent of oxygen, and the reduction in carbon monoxide formed in the absorption of oxygen from air was remarkable, as little as 0.002 to 0.003 percent being generated.

In method 4 the pyrogallol crystals were added, while stirring, to the saturated potassium hydroxide solution in an ice bath at $8^{\circ} \mathrm{C}$. The solution remained in the bath until it reached room temperature. With 21 percent of oxygen, this solution yielded about the same amount of carbon monoxide as in method 3 ; with 80 percent of oxygen, the yield was appreciably less.

Method 5 was found to be the most convenient. The absorption pipette containing the pyrogallol crystals was nearly immersed in an ice bath, and the saturated solution of potassium hydroxide, at room temperature, was added. This solution remained in the bath until it reached room temperature. The reproducibility in the amount of carbon monoxide formed by solutions prepared according to this method was very satisfactory, 
and the yield of carbon monoxide was low, about 0.002 to 0.004 percent. None of the solutions showed variations in the amount of carbon monoxide formed that were greater than those that occurred in different analysis made with a single solution. The reproducibility will be discussed in more detail later.

\section{(b) Composition}

The composition for the solutions studied in this investigation are given in table 1, and reference to the solutions of these compositions will be made only by number. The table is arranged to show the manner of preparing the solutions as well as the composition.

Although the pyrogallol solutions represented in figure 3 were prepared according to the old method, they may be used to illustrate the general effect of changing the concentrations of potassium hydroxide and pyrogallol in solutions, if the obviously erratic runs are eliminated. In solutions S-1 through $\mathrm{S}-5$, the pyrogallol remained constant while the concentration of potassium hydroxide became progressively less. Solution S-1 yielded 0.002 to 0.006 percent of carbon monoxide, and as the alkalinity decreased, the carbon monoxide produced became greater until in $\mathrm{S}-5$ about 0.01 to 0.02 percent of carbon monoxide was formed during air analyses.

The concentration of potassium hydroxide remained constant in solutions $6,7, \mathrm{X}$, and 10 , but the weight of pyrogallol was varied (see table 1). The changes in the concentration of pyrogallol (in the solutions used) apparently did not affect the amount of carbon monoxide produced during absorptions of the oxygen in air. This fact was also supported by the analyses in figure 5, which represents solutions prepared according to the improved method. The soultions represented by blocks 1 and 2 contained $17 \mathrm{~g}$ of pyrogallol per $100 \mathrm{ml}$ of saturated potassium hydroxide solution and were prepared in the same pipettes as those in blocks 5 and 10, the solutions of which contained only $14 \mathrm{~g}$ of pyrogallol per $100 \mathrm{ml}$ of saturated potassium hydroxide solution.

Increased viscosity and clotting occurred sooner in solutions having higher concentrations of pyrogallol. The clotting impaired the efficiency of the distributor pipettes by reducing the number of openings through which bubbles could escape, by trapping the fine bubbles in the viscous solu- tion, and by reducing the rate of flow of the sample into the solution. Finally, the distributor openings became plugged and no gas at all could be bubbled into the solution. In all solutions shown in figure 5, except block 1, oxygen was absorbed by the solution until the distributor became so badly plugged that the sample could not be passed into solution at a rate greater than 40 $\mathrm{ml} / \mathrm{min}$. At least twice as much oxygen was absorbed by S-Z (blocks 5 and 10) as by S-X because of the delay in clotting, which resulted from a decrease in pyrogallol content.

It was previously stated that in solutions prepared by the old method no significant difference was found in the amount of carbon monoxide evolved during oxygen absorptions when different platinum-disk pipettes were used. However, when the solutions were prepared by the improved method, the data shown in figure 5 , blocks $1,2,5$, and 10 , where pipettes $\mathrm{SG}-1$ and $\mathrm{SG}-2$ were used, indicate that in the initial absorptions of 80 percent of oxygen, 0.012 to 0.017 percent of carbon monoxide was formed, and in all the other pipettes the corresponding absorptions yielded only 0.004 to 0.008 percent of carbon monoxide. All of the sintered-glass bubbler pipettes were supposed to be identical, but pipettes $\mathrm{SG}-1$ and $\mathrm{SG}-2$ were purchased at a different time from the others and there may have been some difference in the sintered-glass bubblers.

Two or three drops of an antifoamer, 2-ethyl hexanol, were added to the solutions represented in blocks 3, 5, 7, and 9. No undesirable effects were observed as a result of its use, and it reduced the excessive foaming present when the solutions were new and of relatively low viscosity.

\section{(c) Age}

The age of a solution may refer to its age in time or to the extent to which it is expended. It may be seen in figure 6 that the aging of a solution before oxygen absorptions were begun had no significant effect upon the amount of carbon monoxide produced. The graphs on the left represent solutions, $\mathrm{S}-\mathrm{X}$, that were prepared according to the old method in a plain bubbler pipette. No significant variation in carbon monoxide formed is noted from 1 to 8 days. The erratic result at 6 days is an illustration of the vagaries to be expected when solutions are prepared from the same formula by the old method. 

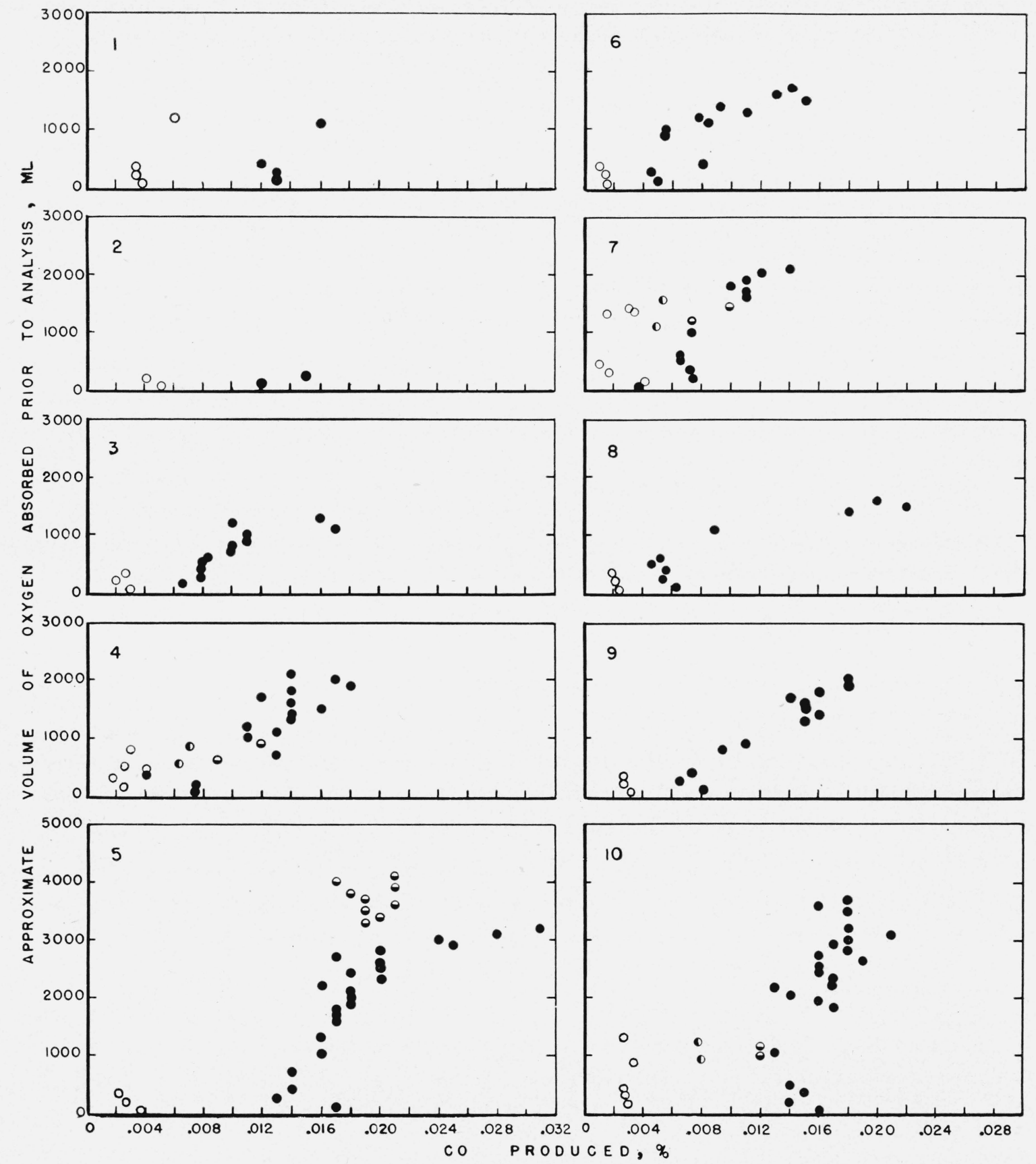

Figure 5. Percentage of carbon monoxide produced during absorptions of oxygen by solutions $S-X$ and $S-Z$ prepared by the improved method in various sintered-glass bubbler pipettes.

1, S-X, SG-1 (not taken to completion) :2, S-X, SG-2; 3, S-X, SG-1a (antifoamer); 4, S-X, SG-3; 5, S-Z, SG-1 (antifoamer); 6, S-X, SG-7; 7, S-X, SG-9

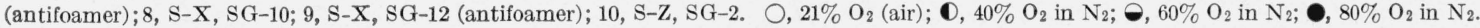



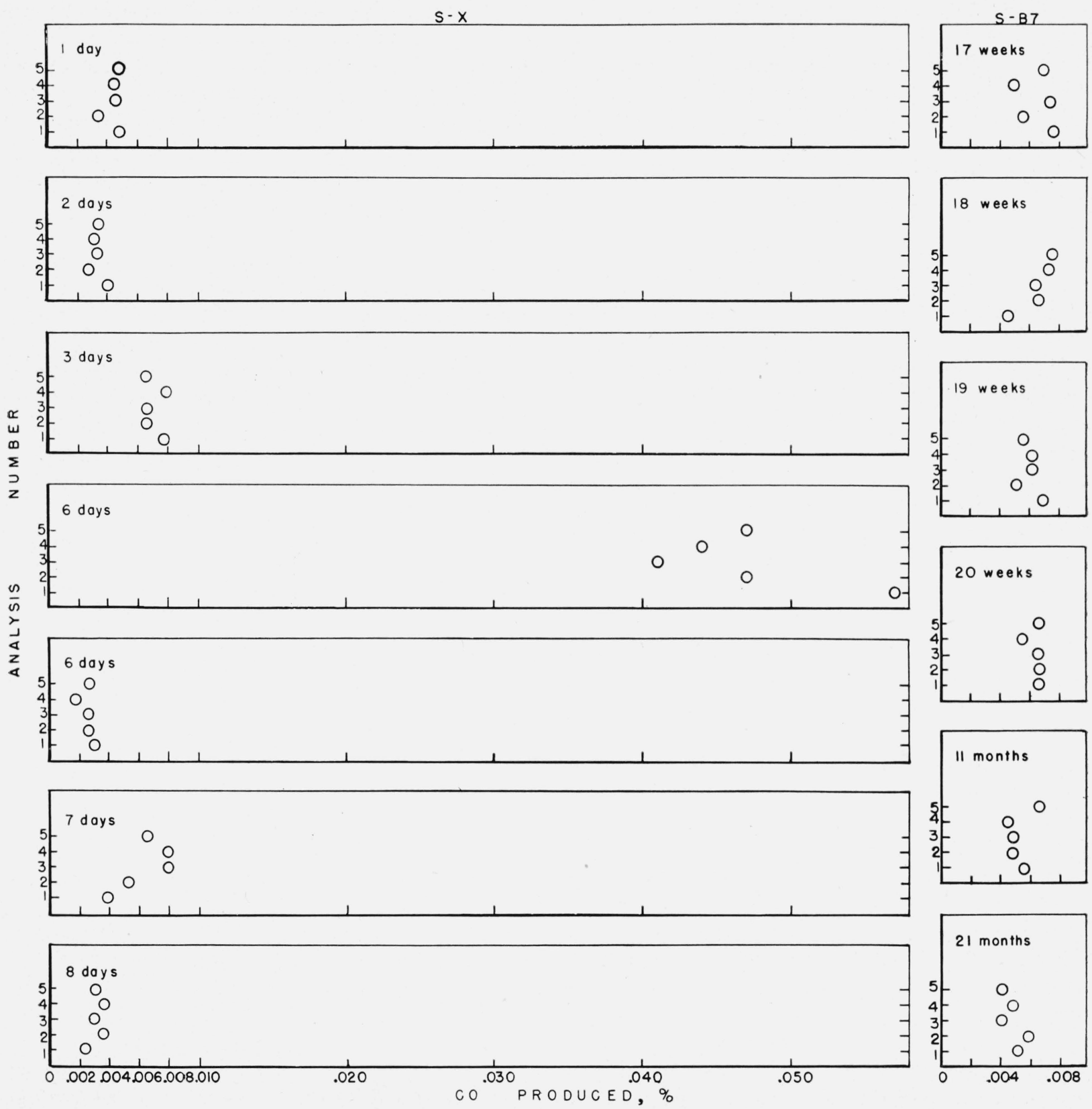

Figure 6. Percentage of carbon monoxide produced during absorptions of oxygen from air by solutions $S-X$ and $S-B 7$, which were prepared by the old method.

The preliminary age of the solution is shown in the upper left-hand corner of each block. 
The plots on the right-hand side of figure 6 show more conclusively that age has no effect. Two liters of solution B7 was prepared in an Erlenmeyer flask by the old method. The flask, on which the glass cap was sealed with paraffin, was stored out of direct sunlight for 17 weeks. About $150 \mathrm{ml}$ of the solution was then transferred to a plain bubbler pipette, and the flask was again sealed and stored. This procedure was repeated when the age of the solution was that indicated in the graphs. Air analyses were made with each portion of this solution, and it was found that no significant change had occurred in the amount of carbon monoxide produced by solutions that were stored from 17 weeks to 21 months.

The relationship between the carbon monoxide produced and the total volume of oxygen absorbed at the point of analysis is shown in figure 5. At first there is a gradual increase in the amount of carbon monoxide formed as more oxygen is absorbed, and, in most cases, there is a rather sharp increase in the amount of carbon monoxide produced after about $800 \mathrm{ml}$ of oxygen absorbed by $\mathrm{S}-\mathrm{X}$ and after about $2,500 \mathrm{ml}$ of oxygen absorbed by $\mathrm{S}-\mathrm{Z}$.

\section{Effect of Partial Pressure of Oxygen}

The graphs of figure 7 show the amount of carbon monoxide produced by five partial pressures of oxygen when absorbed by pyrogallol solutions prepared according to the old method in three types of pipettes. ${ }^{2}$ Since the old metbod of preparing solutions could not be relied upon to give consistent results from one run to another, these graphs may not show exactly the effect of the type of pipette upon the amount of carbon monoxide produced, although the Orsat contact pipette does show the characteristically high production of carbon monoxide. The graphs may be used to indicate the relative effects of several partial pressures of oxygen ranging from 21 to 100 percent of oxygen at various stages in the life of the solution. The broken lines in figure 7 separate the points into groups according to the partial pressure of oxygen absorbed. They show more clearly the fan-shaped effect that results from plotting amounts of carbon monoxide produced during absorptions of various partial pressures of oxygen versus the degree to which the solution was ex-

2 The letters in the upper left-hand corner indicate the type of pipette used. For the key to abbrevatiations, see the legend of figure 2. pended. The same effect was shown in figure 5, although it was less well defined with respect to the total amount of oxygen absorbed in the solutions prepared by the improved method.

In figure 8 is a comparison of the carbon monoxide produced in the absorption of various partial pressures of oxygen by a solution prepared by the old method and one prepared by the improved method. In the latter, the amount of carbon monoxide produced was directly proportional to the partial pressure of oxygen absorbed. In the solution prepared by the old method the carbon monoxide produced increased with the partial pressure of oxygen, but there was not the simple linear relationship that was observed with the improved solution.

Since the volumes of the samples used were constant, the amounts of carbon monoxide formed were directly proportional to the total amount of oxygen absorbed and independent of the partial pressures of oxygen in the samples. This permits a close estimate of the carbon monoxide yield and, therefore, the proper correction for any determined analytical condition.

\section{Effect of Temperature of Reaction}

Figure 9 illustrates the effect of temperature variations in four different solutions that were prepared according to the improved method. The numbers next to the symbols in these graphs indicate the order in which the analyses were performed. A variation of 7 or $8 \mathrm{deg}$. $\mathrm{C}$ in the temperature of reaction was necessary to change significantly the amount of carbon monoxide formed in the absorption of oxygen by pyrogallol solutions. There was a definite relationship between the temperature of reaction and the amount of carbon monoxide formed, although under most laboratory conditions the effect of temperature changes would be negligible.

\section{Effect of Rate of Flow}

The formation of carbon monoxide was significantly increased only when the rate of flow of the original sample was less than $20 \mathrm{ml} / \mathrm{min}$, at which rate about 5 minutes was required to make one pass into the solution. So slow a rate would be considered impractical for most volumetric gas analyses. Figure 10 shows the amount of carbon monoxide formed at various rates of flow. 


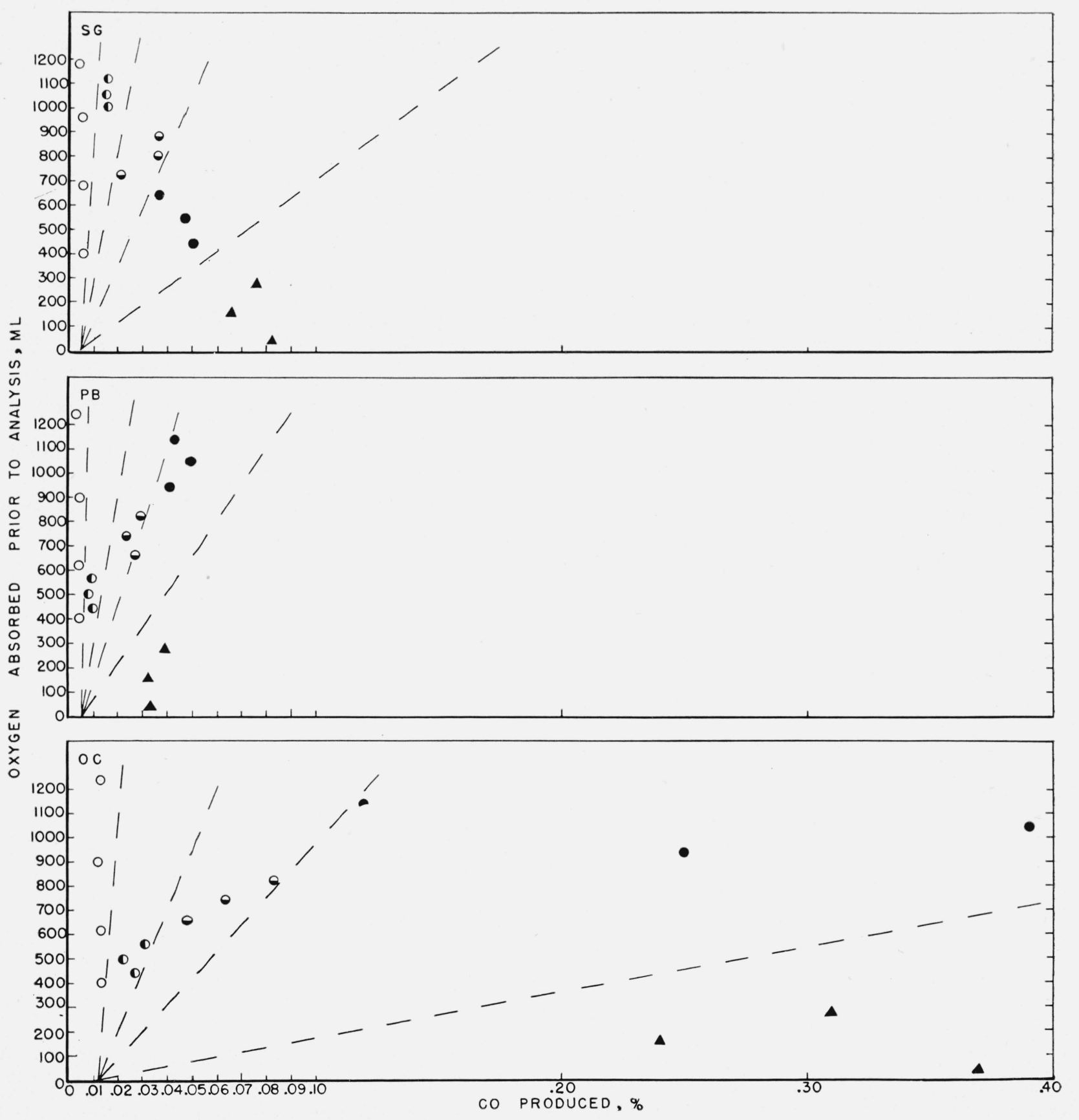

Figure 7. Percentage of carbon monoxide produced in the absorptions of oxygen at various partial pressures, by solutions of the same composition prepared by the old method.

The type of pipette is given in the upper left-hand corner of each block (see fig. 2). $\mathrm{O}, 21 \% \mathrm{O}_{2}(\mathrm{air}) ; \mathbf{O}, 40 \% \mathrm{O}_{2}$ in $\mathrm{N}_{2} ; \boldsymbol{\ominus}^{\prime}, 60 \% \mathrm{O}_{2}$ in $\mathrm{N}_{2} ; \boldsymbol{O}_{, 80 \%} \mathrm{O}_{2}$ in $\mathrm{N}_{2} ; \mathbf{\Lambda}, 100 \% \mathrm{O}_{2}$. 


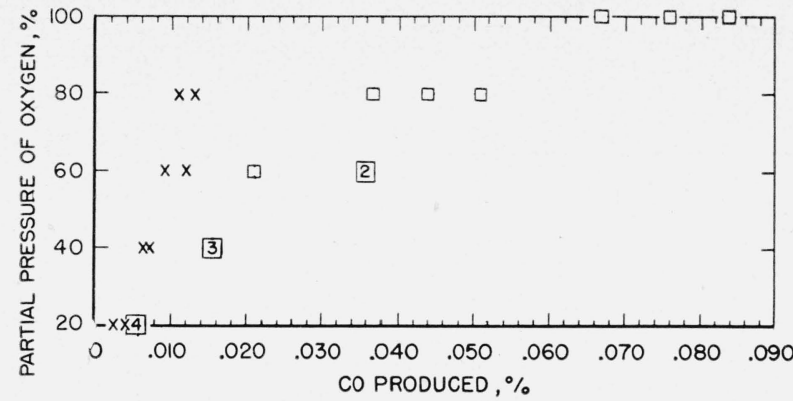

Figure 8. Percentage of carbon monoxide produced in the absorption of oxygen at various partial pressures by two solutions of $S-X$ prepared in a sintered-glass bubbler pipette, one according to the improved method and the other according to the old method.

Numbers inside of squares indicate the number of points at this location; plain squares indicate one point. $\mathrm{X}$, Improved solution; $\square$, old solution
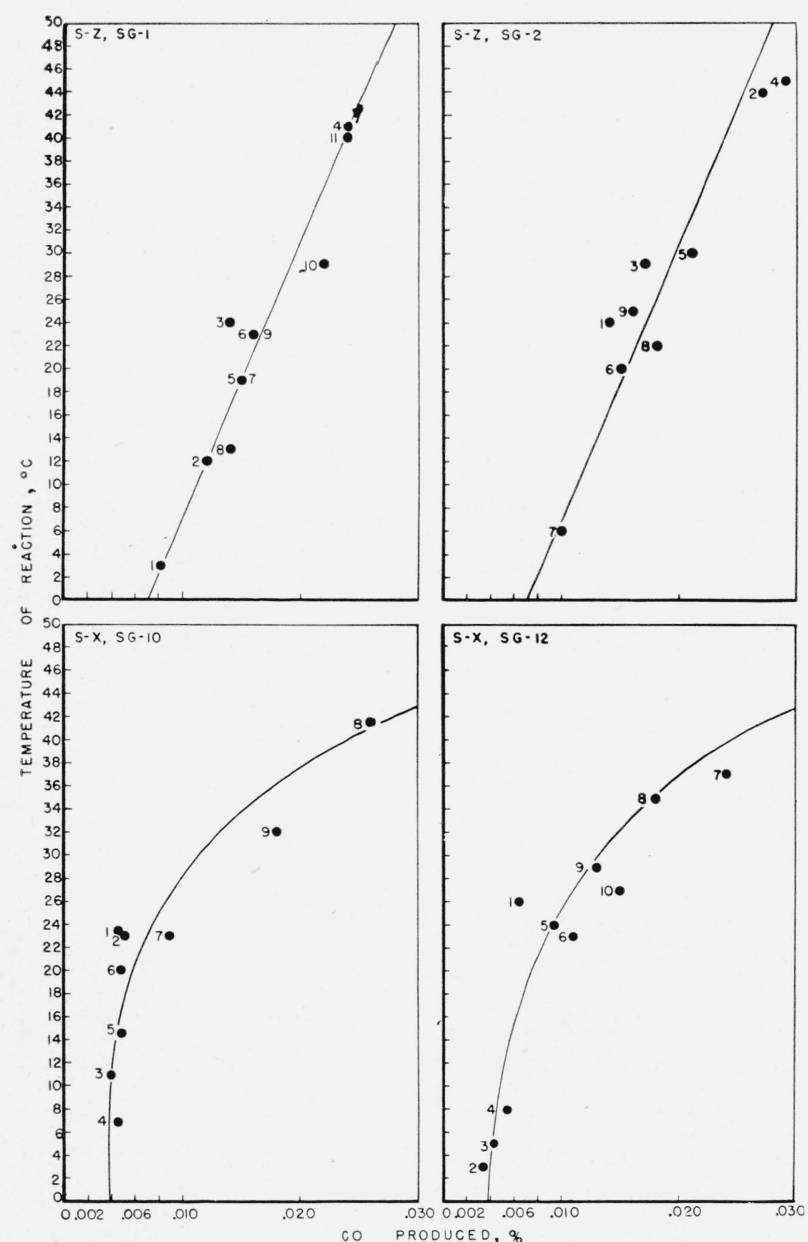

Figure 9. Percentage of carbon monoxide produced at various temperatures of reaction during the absorption from mixtures containing 80 percent of oxygen.

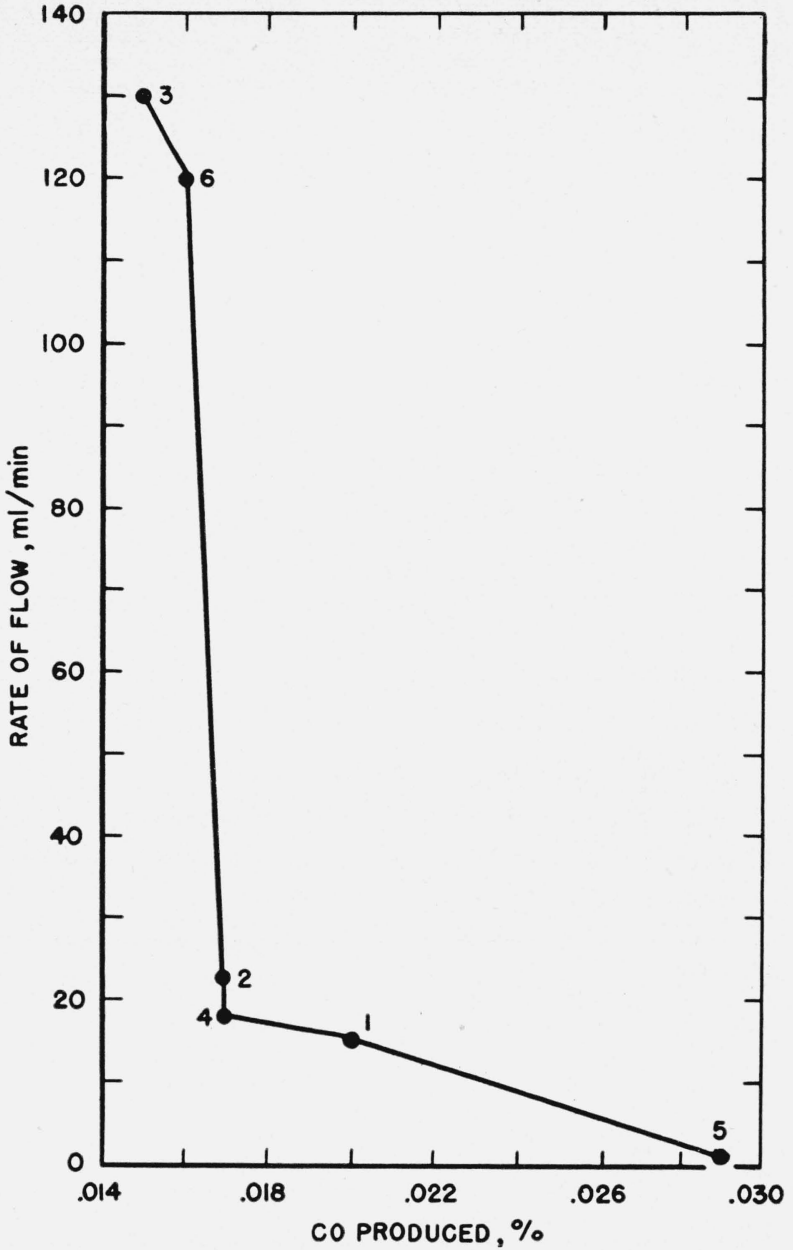

Figure 10. Percentage of carbon monoxide produced at various rates of flow of a mixture containing 80 percent of oxygen into pipette $S G-1$ containing solution $S-X$.

The numbers next to the symbols indicate the order in which the analyses were performed.

It will be shown later in section 6 that the contact type of pipette caused a much greater production of carbon monoxide than did the bubbler type. This indicated that carbon monoxide was formed when high partial pressures of oxygen came in contact with expended pyrogallol solution on the glass walls. If this assumption were true, it would follow that a reduction in the rate of flow of the sample would cause a greater production of carbon monoxide in the bubbler type of pipettes, because the oxygen would be in contact longer with the expended solution adhering to the inlet capillary tube leading to the bubbler. This seems to be a logical explanation of the data presented in figure 10 . 


\section{Effect of Number of Passes Into Pyrogallol}

The efficiency of oxygen absorption in the platinum-disk bubbler pipette has been previously determined [5]. In the work referred to it was found that in the analysis of a mixture containing 95 percent of oxygen, more than 70 percent of the total oxygen in the sample was removed during the first pass and about 93 percent had been removed after the second pass. It may therefore be assumed that any significant amount of carbon monoxide was formed in the first two passes, since, for any one reagent at one temperature, the partial pressure of oxygen is the most important factor in the formation of carbon monoxide. The graphs on the left of figure 11 show the amount of oxygen absorbed during the number of passes cant amount of carbon monoxide after the second pass when about 6 percent of oxygen remained in the residue. When a mixture containing 80 percent of oxygen was absorbed by this solution, erratic results were obtained in the two analyses made with five passes. This may be explained by the fact that about $1,200 \mathrm{ml}$ of oxygen had been previously absorbed and the breaking point in the absorption curve had been reached, causing less efficient absorption of oxygen as well as a larger yield of carbon monoxide.

\section{Effect of the Design of the Absorption Pipette}

For the determination of the effect of several types of absorption pipettes upon the amount of carbon monoxide produced, the improved method
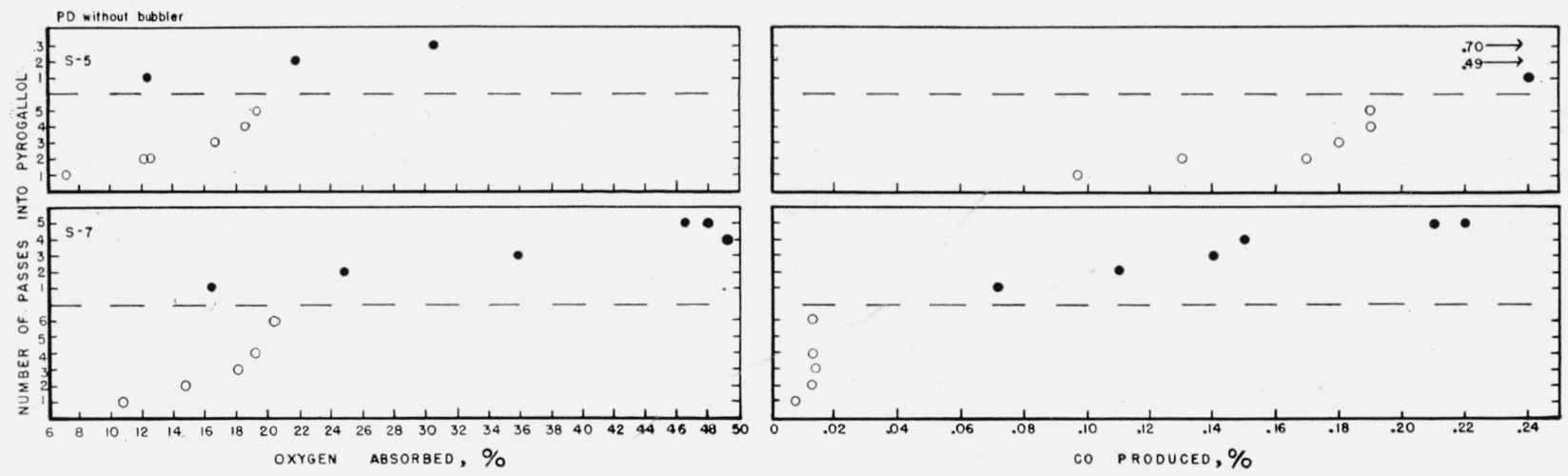

FIGURE 11. Percentage of carbon monoxide produced and oxygen absorbed during varying numbers of passes of sample into pyrogallol.

A platinum-disk bubbler pipette was used, but the bubbler was not employed in order to exaggerate the desired effect. $\bigcirc, 21 \% \mathrm{O}_{2}$ (air); $\bullet$, $80 \% 02$ in $\mathrm{N}_{2}$.

indicated. The graphs on the right show the amount of carbon monoxide formed during those absorptions. In order to exaggerate the effect, the bubbler was not used and the sample was passed into the pipette on top of the solution. The weakly alkaline solution $\mathrm{S}-5$ in an absorption from gas containing 80 percent of oxygen absorbed about 10 percent of oxygen on each of the first three passes, and the amount of carbon monoxide formed was almost directly proportional to the oxygen absorbed. Furthermore, absorptions of oxygen in air made with this solution showed no significant amount of carbon monoxide produced after the fourth pass when only about 2 percent of oxygen remained in the residue.

In the absorption of oxygen from air, the strongly alkaline solution, S-7, yielded no signifi- was used in preparing 2 liters of solution $\mathrm{S}-\mathrm{Z}$ in an Erlenmeyer flask. Two hundred $\mathrm{ml}$ of this solution was siphoned, in an atmosphere of nitrogen, into each of the nine pipettes illustrated in figure 2, and absorptions from mixtures of 21 and 60 percent of oxygen were made in each of the pipettes. The carbon monoxide evolved is shown in figure 12. The Orsat contact pipette was the only one that showed any great deviation from the others in the amount of carbon monoxide produced. The sintered-glass bubbler, BranhamSperling bubbler, and platinum-disk bubbler pipettes produced the smallest amounts of carbon monoxide. The Dennis-Friedrichs pipette may also be included in this group with the note that the carbon monoxide formed might have been slightly less, except that the rate of flow of sample 

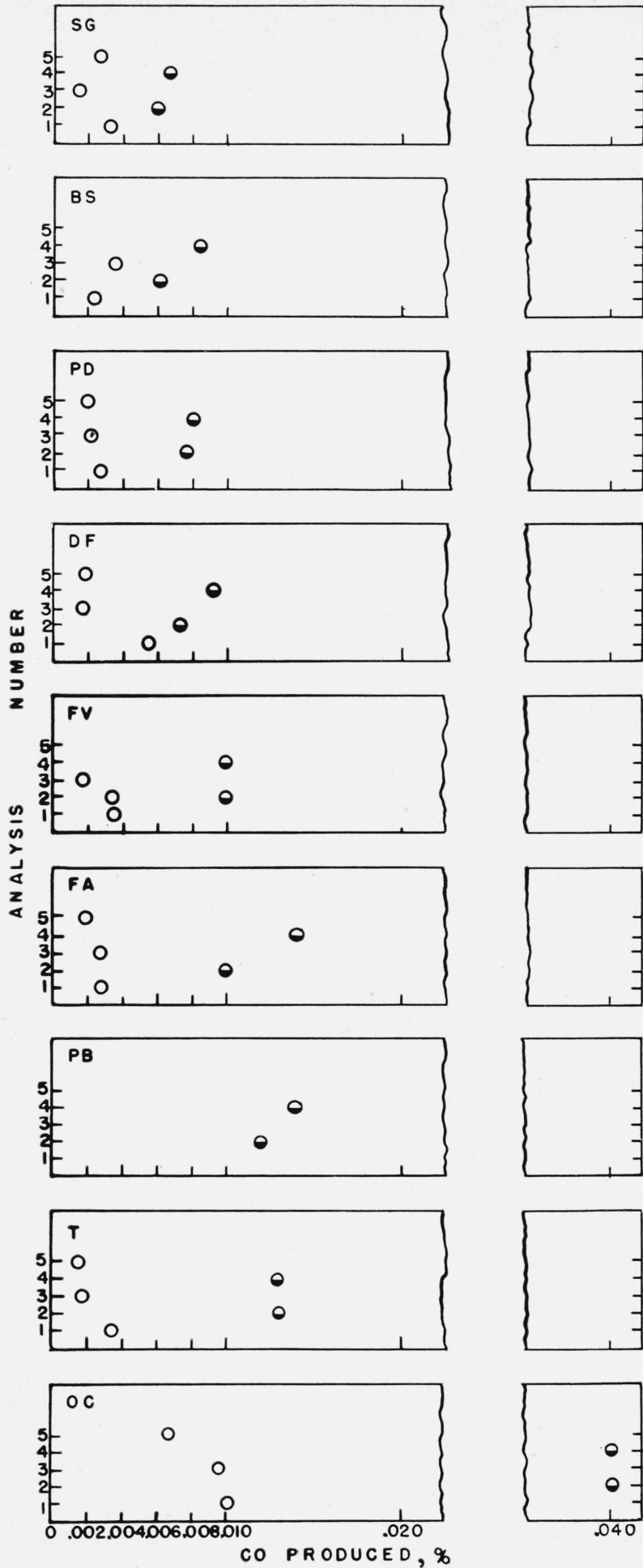

Figure 12. Percentage of carbon monoxide produced during the absorption of oxygen by solution $S-B Z$ in various types of absorption pipettes (see fig. 2).

Length of stem of bubbler: SG, $18.5 \mathrm{~cm}$; BS, $19 \mathrm{~cm}$; PD, $20 \mathrm{~cm}$; DF, $19 \mathrm{~cm}$; FV, $15 \mathrm{~cm}$; FA, $14 \mathrm{~cm}$; PB, $13 \mathrm{~cm}$; T, $10.5 \mathrm{~cm}$. $\bigcirc, 20 \% \mathrm{O}_{2}$ (air); ๑. $60 \% \mathrm{O}_{2}$ in $\mathrm{N}_{2}$. was reduced to about one-half of the usual rate. This had to be done to prevent the sample from passing to the atmospheric arm of the pipette. Figure 12 shows, in general, that the amount of carbon monoxide formed is a function of the depth of the pyrogallol solution above the bubbler and/or the size of the gas bubbles.

It appears that there may be a correlation between the formation of carbon monoxide and the depth of pyrogallol solution through which the bubbles travel. In the first four pipettes, the distance from the bubbler tip to the top of the solution was $18.5 \mathrm{~cm}$ or more, and the carbon monoxide formed in the absorption from a mixture containing 60 percent of oxygen was 0.006 to 0.009 percent; in the next four pipettes where the bubbles traveled from 10.5 to $15 \mathrm{~cm}$ in solution, the carbon monoxide produced during similar absorptions was 0.010 to 0.014 percent. When the depth of the solution above the bubbler was decreased the effect became more pronounced, therefore, it appears to be desirable to have at least $18 \mathrm{~cm}$ of solution above the bubbler.

For a minimum production of carbon monoxide it is probably also desirable to distribute the sample in fine bubbles. The sintered-glass bubbler, Branham-Sperling bubbler, and platinumdisk bubbler pipettes, which produced the least carbon monoxide, distribute the gas in many very fine bubbles. The Fisher valve-bubbler and Francis auto-bubbler pipettes produce bubbles of an intermediate size, and the plain bubbler pipette has the largest bubbles. The DennisFriedrichs pipette is not comparable with the others because of the long spiral up which the bubbles travel, and the Tramm pipette combines the contact method of absorption with the bubbling method. The large amount of carbon monoxide formed in the Orsat contact pipette indicates the importance of distributing the sample in such a way as to prevent its contacting excessive amounts of expended solution.

Shepherd has shown that distributors of fine bubbles are the most efficient for the absorption of oxygen [5]. However, since the bubble size may not affect the carbon monoxide formed by an amount significant to many analyses, some may find it desirable to avoid the trouble caused from plugged distributors by using the plain bubbler with a larger number of passes for the complete absorption of oxygen. 


\section{Conclusions}

The accuracy, reproducibility, and rapidity of the analytical determination of oxygen by absorption in alkaline pyrogallol may be improved as indicated by this experimental study.

(1) Solutions can be prepared that evolve no significant amount of carbon monoxide during the usual analysis. This is accomplished by the direct addition of a saturated solution of potassium hydroxide to pyrogallol crystals under conditions such that the heat evolved during the solution is dissipated rapidly.

(2) Samples having partial pressures of oxygen higher than 50 percent can be analyzed with the improved solutions without dilution of the sample.

(3) The solution should not be used for analysis after the absorption of 12 volumes of oxygen per volume of solution if high accuracy is desired.

(4) The temperature of the pyrogallol reagent should not exceed $30^{\circ} \mathrm{C}$ during absorption.

(5) The rate of flow of sample into the pyrogallol should be as rapid as possible and never less than $20 \mathrm{ml} / \mathrm{min}$.
(6) A pipette that disperses the gas in fine bubbles through at least $18 \mathrm{~cm}$ of solution is preferable.

It should be emphasized that if the analyst is concerned with amounts of carbon monoxide that are less than about 0.01 percent of the sample, a determination of the carbon monoxide formed should be made after each absorption of oxygen.

The author acknowledges with gratitude the helpful suggestions and advice contributed by Martin Shepherd during this investigation.

\section{References}

[1] J. R. Branham and M. Sucher, J. Research NBS 21, 63 (1938) RP1113.

[2] M. Shepherd, Anal. Chem. 19, 77 (1947).

[3] M. Shepherd, BS J. Research 6, 121 (1931) RP266.

[4] M. Shepherd, J. Research NBS 26, 351 (1941) RP1382.

[5] M. Shepherd, BS J. Research 4, 747 (1930) RP177.

Washington, March 31, 1950. 